\title{
Metformin in the management of patients with diabetes and advanced heart failure (HFrEF): a propensity score-matched analysis
}

Jan Benes ( $\sim$ jan.benes@ikem.cz )

Institute of Clinical and Experimental Medicine

Martin Kotrc

Institute of Clinical and Experimental Medicine

Katerina Kroupova

Institute of Clinical and Experimental Medicine

Peter Wohlfahrt

Institute of Clinical and Experimental Medicine

Jan Kovar

Institute of Clinical and Experimental Medicine

Janka Franekova

Institute of Clinical and Experimental Medicine

Marketa Hegarova

Institute of Clinical and Experimental Medicine

\section{Lenka Hoskova}

Institute of Clinical and Experimental Medicine

Eva Hoskova

Institute of Clinical and Experimental Medicine

Terezie Pelikanova

Institute of Clinical and Experimental Medicine

Petr Jarolim

Harvard Medical School

Josef Kautzner

Institute of Clinical and Experimental Medicine

Vojtech Melenovsky

Institute of Clinical and Experimental Medicine

\section{Research Article}

Keywords: metformin, heart failure, diabetes mellitus, quality of life, propensity-matched analysis, outcome 
Posted Date: March 8th, 2022

DOI: https://doi.org/10.21203/rs.3.rs-1369199/v2

License: (c) (i) This work is licensed under a Creative Commons Attribution 4.0 International License. Read Full License 


\section{Abstract}

Background: The role of metformin (MET) in the treatment of patients with advanced HFrEF and type 2 diabetes mellitus (DM) is not firmly established. We studied the impact of MET on metabolic profile, quality of life (QoL) and survival in these patients.

Methods: A total of 847 stable patients with advanced HFrEF (57.4 \pm 11.3 years, $67.7 \%$ NYHA III/IV, LVEF $23.6 \pm 5.8 \%$ ) underwent clinical and laboratory evaluation and were prospectively followed for a median of 1126 (IQRs $410 ; 1781$ ) days for occurrence of death, urgent heart transplantation or mechanical circulatory support implantation.

Results: A subgroup of 380 patients (44.9\%) had DM, 87 of DM patients $(22.9 \%)$ were treated with MET. Despite worse insulin sensitivity and more severe DM (higher BMI, HbA1c, worse insulin resistance), METtreated patients exhibited more stable HF marked by lower BNP level (400 vs. $642 \mathrm{ng} / \mathrm{L}$ ), better LV and RV function, lower mitral and tricuspid regurgitation severity, were using smaller doses of diuretics (all $p<$ 0.05). Further, they had higher eGFR (69.23 vs. $\left.63.34 \mathrm{ml} / \mathrm{min} / 1.73 \mathrm{~m}^{2}\right)$ and better QoL (MLHFQ: 36 vs. 48 points, $p=0.002$ ).

Compared to diabetics treated with other glucose-lowering agents, MET-treated patients had better eventfree survival even after adjustment for BNP, BMI and eGFR ( $p=0.035)$. Propensity score-matched analysis with 17 covariates yielded 81 pairs of patients and showed a significantly better survival for MET-treated subgroup $(p=0.01)$.

Conclusion: MET treatment in patients with advanced HFrEF and DM is associated with better quality of life and improved outcome, by mechanisms beyond the improvement of blood glucose control.

\section{Introduction}

Type 2 diabetes mellitus (DM) is a common and severe comorbidity in patients with heart failure with reduced ejection fraction (HFrEF), but optimal treatment modality has not yet been clarified. Biguanides including metformin (MET) had long been considered contraindicated in HF patients due to concerns about lactic acidosis, that was observed with phenformin, an older biguanide with less favorable pharmacological profile. ${ }^{1}$ Large meta-analysis, however, have not demonstrated an association between MET therapy and increased risk of lactic acidosis, ${ }^{2}$ so MET has been used even in HF population. Observational studies showed not only MET safety in HF subjects ${ }^{3,4}$ but some studies even suggested a survival benefit associated with this drug. ${ }^{5-7}$ However, there is only one study analyzing MET specifically in patients with $\mathrm{HFrEF}^{8}$ and the absence of a randomized trial is a major limitation for MET use. Moreover, registry-based retrospective studies lack a precise characterization of analyzed patients (echocardiography, laboratory analysis including metabolic profile). Therefore, the mechanism of MET action in this population is speculative. 
The aim of the present study was to evaluate the association between MET treatment and metabolic profile, quality of life and outcome in prospectively followed advanced HFrEF patients.

\section{Methods}

\section{Study subjects}

Patients with stable HFrEF (LVEF <40\%) were enrolled in the study between 2008 and 2016 in a prospectively defined registry. Patients had to have at least 6-month history of HFrEF and had to receive stable medical therapy for at least three months. Subjects with potentially reversible LV dysfunction (planned valve surgery, revascularization, or tachycardia-induced cardiomyopathy) were excluded.

Patients were followed until July 2019. DM was diagnosed according to current recommendation ${ }^{9}$ either as a patient's history of known DM, or Hb1Ac $\geq 48 \mathrm{mmol} / \mathrm{mol}$ ( $\geq 6.5 \% \mathrm{NGSP} / \mathrm{DCCT}$ ) if DM was undetected before the study enrollment. The investigation conforms with the principles outlined in the Declaration of Helsinki, the study protocol was approved by the Institutional Ethics Committee and all subjects signed an informed consent.

At the study enrollment, patients completed a Minnesota Living with Heart Failure Questionnaire (MLHFQ) and had anthropometric tests and underwent an echocardiographic study (Vivid-7; General Electric, Milwaukee, Wisconsin). LV function and dimensions were measured according to recommendations. ${ }^{10}$ Mitral and tricuspid regurgitations were assessed semiquantitatively and expressed in 3 grades (mild, moderate, significant).

Right ventricular dysfunction was quantified (0 to 3) in an apical 4-chamber view by using tricuspid annular systolic excursion (M-mode TAPSE) ${ }^{11}$ and tissue systolic velocity $(\mathrm{Sm})^{12}$ with the following cutoffs: RVD0, normal: TAPSE >20 mm, Sm >12 cm/s; RVD1, mild impairment: TAPSE 16 to $20 \mathrm{~mm}$, Sm 9 to $12 \mathrm{~cm} / \mathrm{s}$; RVD2, moderate: TAPSE 10 to $15 \mathrm{~mm}, \mathrm{Sm} 6$ to $9 \mathrm{~cm} / \mathrm{s}$; and RVD3, severe: TAPSE severe: TAPSE $<10 \mathrm{~mm}, \mathrm{Sm}<6 \mathrm{~cm} / \mathrm{s}$. In case of disagreement of criteria, qualitative visual estimation of RV motion in apical 4-chamber was also taken into account.

\section{Follow-up}

The study was conducted in a tertiary cardiac center offering heart transplantation program and implantation of mechanical circulatory the support. Therefore, an adverse outcome was defined as the combined endpoint of death, urgent heart transplantation (HTx) or mechanical circulatory support (MCS) implantation. ${ }^{13}$ As the time to non-urgent $\mathrm{HTx}$ reflects primarily donor availability rather than recipient's condition, patients who received a non-urgent HTx were censored as having no adverse event at the day of HTx.

\section{Laboratory assessment}


Blood was collected into serum separator tubes and EDTA-containing tubes upon patient enrollment. Basic biochemical parameters were assessed at the Institute for Clinical and Experimental Medicine. BNP was measured on the ARCHITECT analyzer (Abbott Diagnostics, Abbott Park, Illinois) using a chemiluminescent immunoassay. HbA1c was measured on Tosoh analyser G8 (Tosoh Corporation, Tokyo, Japan) by automated high performance liquid chromatography. High-sensitivity troponin T was measured on the Cobas analyser e601 (Roche Diagnostics, Mannheim, Germany). Estimated glomerular filtration rate (eGFR) was calculated using CKD-EPI 2009 equation.

Insulin and C-peptide were measured using IRMA kits (Beckman Coulter, Prague, Czech Republic) and glucagon using RIA kit (EMD Millipore Corporation, St. Louis, Missouri, USA).

GDF-15 was measured using the Quantikine Human GDF-15 Immunoassay (R\&D Systems Inc, Minneapolis, MN). Insulin resistance was estimated by HOMA-IR (homeostatic model assessment of insulin resistance) calculated as fasting glucose $(\mathrm{mmol} / \mathrm{l}) \times$ fasting immunoreactive insulin $(\mathrm{microlU} / \mathrm{ml})$ /22.5. ${ }^{14}$

\section{Statistical analysis}

Data are presented as mean \pm standard deviation, median with interquartile ranges (IQRs), or frequency (percent). Unpaired t-test or Mann-Whitney test were used to compare continuous variables between groups as appropriate. Kolmogorov-Smirnov test was used to evaluate Gaussian distribution. Chisquare test was employed to compare categorical variables. The effect of biomarker concentration on prognosis was tested using univariate and multivariable Cox model. Event-free survival of patients was analyzed by Kaplan-Meier analysis with log-rank test comparison between groups.

Propensity score matching was used to account for differences in characteristics of patients with and without MET. The propensity score for each patient was calculated using a multivariable logistic regression model in which the MET use was regressed on 17 characteristics (see Results) that might influence the selection of MET therapy or that have been shown to influence prognosis of patients with advanced HF. Subjects were matched on the logit of the propensity score using 1:1 greedy nearestneighbor matching with a caliper distance of 0.2 times the SD of the logit of the propensity score. Success of matching was assessed by computing the standardized mean difference of each covariate. To compare mortality between the 2 matched groups we have used the McNemar test and matched pairs stratified Cox proportional hazards model with a robust variance estimator. The proportional hazard assumption was tested and fulfilled. All tests were 2 -sided, and $p$ values $<0.05$ were considered significant. Calculations were performed using JMP 11 (SAS Institute Inc., Cary, NC) and R (Vienna, Austria).

\section{Results}

\section{Patients}


A total of 847 advanced HFrEF patients $(67.7 \%$ were in with NYHA III/IV, average LV-ejection fraction was $23.6 \%, 44.9 \%$ had moderate/severe RV dysfunction), were enrolled in the study (Fig.1). Enrolled patients achieved high level of guideline-recommended HF pharmacotherapy and device therapy (Table 1). Patients were prospectively followed for a median of 1126 (IQRs 410; 1781) days. During follow-up, 515 patients $(60.8 \%)$ experienced an adverse outcome.

A total of 380 patients (44.9\%) were found to have DM, 467 patients (55.1\%) were DM free. All DM patients had type $2 \mathrm{DM}$; none of the patients had type $1 \mathrm{DM}$. DM patients were older, had more often CAD as underlying HF etiology, larger body mass index, worse renal function (Table 1) and worse cumulative survival - 269 (70.8\%) DM vs. 246 (52.7\%) non-DM patients experienced an adverse outcome, median time to event was 879 days (IQRs 312; 1631) for DM patients compared with 1270 (IQRs 467; 2010) days for non-DM counterparts. Kaplan-Meier curves are provided in Fig. 1 in the Online Supplement.

\section{Diabetes treatment}

Out of 380 DM patients, 153 patients (40.3\%) were treated with diet only, 87 patients (22.9\%) with MET, 67 patients (17.6\%) with sulfonylurea (SU) derivatives, 108 patients (28.4\%) with insulin, 26 patients (6.8\%) with DPPIV-inhibitors, 3 patients $(0.8 \%)$ with repaglinide and 1 patient $(0.3 \%)$ was treated with liraglutide. In 3 patients the information about the treatment was missing. None of the patients was treated with thiazolidinediones, acarbose or SGLT2-inhibitors. 31 patients $(8.2 \%)$ were treated with more than one peroral antidiabetics (PAD), 26 patients $(6.8 \%)$ with the combination of PAD and insulin. More detailed information about DM treatment is given in Table 1 and Fig. 2.

In patients treated with MET, the most widely used MET dose was $1000 \mathrm{mg}$ (29 patients, 33.3\%). 18 patients $(20.7 \%)$ were taking a dose lower than $1000 \mathrm{mg}, 14$ patients $(16.1 \%)$ a dose between 1000 and $2000 \mathrm{mg}$ and 25 patients (28.8\%) were taking $2000 \mathrm{mg}$ daily or higher. The information about MET daily dose was missing in 1 patient (1.1\%). Distribution of MET daily dose is in Fig. 2 in the Online Supplement. Compared with MET-free counterparts, MET-treated DM patients had better LV function (LVEF), RV function and lower both mitral and tricuspid regurgitation severity, better renal function and larger BMI. They were using smaller diuretic doses but achieved similar level of guideline-recommended HF pharmacotherapy, had comparable rate of ICD and CRT treatment and similar hemodynamic profile (Table 1). MET-treated patients were more often treated with SU derivatives and DPPIV-inhibitors; no significant difference was found for insulin treatment.

\section{Metabolic profile of MET-treated patients}

Analysis of metabolic parameters revealed that compared with MET-free counterparts, MET-treated patients had similar levels of fasting glycemia and insulin secretion (C-peptide level), but larger Hb1 Ac level, higher insulin and glucagon level and more pronounced insulin resistance (HOMA-IR), Table 
1 and Figure 3. Further, MET-treated patients had higher level of beta-hydroxybutyrate but similar level of GDF-15 (Fig. 3).

\section{Diabetes treatment and quality of life}

No significant difference was found in QoL between patients with and without DM (Table 1). In DM subgroup, pharmacotherapy with neither insulin, SU derivatives nor with DPPIV-inhibitors was associated with better QoL (Table 1 in the Online Supplement). On the contrary, MET treatment was associated with a better QoL (Table 1).

Multivariable regression analysis identified MET treatment together with BNP and BMI, but not eGFR, SU derivatives treatment, DPPIV-inhibitors treatment or insulin treatment to be independently associated with MLHFQ score (Table 2 in the Online Supplement). Similar results were obtained for the somatic component of MLHFQ whereas no association of MET treatment with emotional component of the MLHFQ score was found (data not shown).

\section{Diabetes treatment and outcome}

Kaplan-Meier analysis showed that MET-treated diabetic patients had better survival compared to METfree counterparts. Other therapeutic regimes were not associated with any difference in event-free survival (Figure 4). Similarly, Cox proportional hazard model identified MET treatment to be associated with improved outcome. No such relationship was observed for therapy with insulin, SU derivatives or DPPIVinhibitors (Table 3 in the Online Supplement).

Next, we have analyzed whether there was any subgroup having altered benefit from MET treatment. No significant interaction was found between MET therapy and NYHA functional class, LVEF, RV dysfunction grade, BNP level, eGFR, ACEi/ARB treatment, beta-blocker treatment, presence of ICD, or CRT (all p for interaction $\geq 0.20$, Table 4 in the Online Supplement). This suggests that the benefit from MET therapy is preserved regardless of HF severity and independent of HF treatment. Similarly, no significant interaction was found between MET therapy and insulin or DPPIVi treatment ( $p$ for interaction $=0.35$ and 0.95 , respectively). However, borderline interaction was found for SU derivatives treatment ( $p$ for interaction= 0.054). Kaplan-Meier analysis showed borderline worse survival of patients treated with MET and SU derivatives compared with MET without SU derivatives ( $($ log-rank $)=0.08)$.

\section{Adjustment for confounders, propensity score-matched analysis}

Although MET-treated DM patients had better cardiac function, renal function and larger BMI, Cox proportional hazard model analysis revealed that MET treatment was associated with a significantly better outcome even after the adjustment for BNP, eGFR and BMI (Table 2). 
Finally, we have performed propensity score matched analysis that matched the patients for 17 variables that might influence the selection of MET therapy or that have been shown to influence prognosis of patients with advanced heart failure (age, sex, NYHA functional class, BMI, estimated glomerular filtration rate, LVEF, RV dysfunction grade, mitral and tricuspid regurgitation severity, BNP level, beta-blockers use, renin-angiotensin system inhibitors use, ICD therapy, CRT therapy, uric acid levels, treatment with other $\mathrm{PAD} /$ incretins and treatment with insulin). Propensity score matching yielded 81 pairs of patients. Standardized mean differences of matched covariates ranged from 0 to 0.23 , with a standardized median difference of 0.06 (IQR 0.029-0.076). Significantly better survival for MET-treated group was showed both using the McNemar $(p=0.04)$, as well as Cox proportional hazard model $(p=0.01$, Fig. 5$)$.

\section{Discussion}

The results of this study can be summarized as follows: (i) despite worse insulin sensitivity and worse DM compensation in MET-treated patients, MET-treatment was independently associated with both better quality of life and improved outcome in advanced HFrEF patients with DM; (ii) MET treatment was associated with better outcome regardless of HF severity or compensation of diabetes.

Optimal treatment modality in patients with advanced HF and DM is not well established, which is mirrored by the large variability of treatment strategies observed in our study.

Only $22.9 \%$ of our patients were treated with MET, which is likely a consequence of previous recommendations to avoid this drug in $\mathrm{HF}$ because of concerns regarding lactic acidosis risk. ${ }^{15}$ Nevertheless, MET was used in clinical practice and data on MET use in HF patients with DM eventually emerged. One recently published study showed lower risk of hospitalization for HF in MET-treated DM patients. ${ }^{16}$ Thirteen studies have been published describing the association between MET treatment on outcome in patients with established HF and DM. 5,6,8,17-26 However, the majority of studies are retrospective and based on administrative or disease records. ${ }^{6,19-23,25,26}$ Only five of them reported LVejection fraction $5,6,8,19,24$ and only one study focused specifically on patients with LVEF $<40 \%{ }^{8}$ Although meta-analyses of these studies reported mostly better outcome in patients treated with MET, ${ }^{3,4}$ the heterogeneity of studied populations and approaches leave many questions unanswered. None of the studies focused specifically on patients with advanced HF and no study HFrEF patients employed propensity-matching approach. As large randomized controlled trials with MET in HF patients with DM are unlikely to be carried out, ${ }^{27}$ our data offering a prospective observational design of well-characterized cohort employing propensity matching analysis offers the strongest evidence possible. In the propensity matching analysis, we have adjusted the cohort for seventeen possible confounders and our data thus strongly suggest that despite differences between MET-treated and MET-free patients, observed difference in outcome between these groups is indeed attributable to MET therapy.

The mechanism of action of MET is a subject of intense debate. Beneficial effect of MET was first explained by an inhibition of mitochondrial complex $1^{28,29}$ and by an increase in ADP/ATP ratio that activates AMP-dependent protein kinase (AMPK). However, the mechanism of action of MET is likely to 
be more pleiotropic; MET enhances cardiac autophagy, ${ }^{30}$ improves myocardial efficiency and reduces myocardial energy consumption, ${ }^{31}$ and directly modulates the growth and function of gut microbiota. ${ }^{32}$ MET has been also shown to have potent effect on cancer prevention and recurrence ${ }^{33,34}$ and its anticancer effect might be also clinically relevant in HF patients as they are consistently reported to have higher risk of malignancies. ${ }^{35,36}$

Although our study was not designed to unveil the mechanism responsible for overall benefit from MET therapy, our data suggest that the cardioprotection of MET is independent on glycemic control. This is in line with results of the post UKPDS-trial follow-up that showed significant risk reduction by MET in diabetes-related endpoints despite of the loss of between-group differences in glycated hemoglobin. ${ }^{37}$ Experimental studies have similarly shown anti-inflammatory properties of MET irrespective of DM status. $^{38}$

Metabolic abnormalities are observed early in the course of cardiac pathologies. When subjected to pressure overload, the ventricular myocardium shifts from fatty acids to glucose as its main source for energy; this precedes the development of LV hypertrophy. ${ }^{38}$ The excessive glucose metabolism in the cardiomyocytes causes glucose-6-phosphate (G6P) accumulation. G6P activates mammalian target of rapamycin complex 1 (mTORC1), which induces hypertrophy. MET activates AMPK, which inhibits mTROC1, thus preventing LV hypertrophy. ${ }^{38}$ This explains that MET treatment has also been shown to induce regression of LV-hypertrophy and exert anti-oxidant effects even in non-diabetic patients. ${ }^{39}$ Similarly, LV reverse remodeling has been observed in other drugs that activate AMPK such as SGLT2inhibitors. $^{40}$

In non-HF subjects, MET was shown to mediate its effect on body weight and energy balance through GDF-15. ${ }^{41}$ We have not observed increased GDF-15 level in MET-treated compared with MET-free patients in our study, which can be explained by worse cardiac and renal function in MET-free patients. Both cardiac as well as renal dysfunction are associated with higher GDF-15 levels. ${ }^{42}$ MET-treated patients have increased ketone body beta-hydroxybutyrate, a metabolic substrate that is readily utilized by failing heart and that may have favorable effects on bioenergetics. ${ }^{43}$ Infusion of ketone bodies in HFrEF patients was shown to improve cardiac output and LV-ejection fraction. ${ }^{44}$ Interestingly, despite patients on MET had lower neurohumoral activation, we observed higher levels of stress hormone glucagon in MET-treated patients. Is was shown that MET administration to prediabetic subjects resulted in an increase of glucagon. ${ }^{45}$ Higher glucagon in MET-treated patients may be protective against hypoglycemia that is a feared complication of DM treatment and was linked to arrhythmias and increased mortality. ${ }^{46}$

Although QoL was independent of DM status in our study, we have observed a better QoL in MET-treated DM patients and MET was significantly associated with QoL also in multivariable linear regression suggesting its independent effect on QoL. To our best knowledge, this is the first study that analyzed the QoL with respect to MET treatment using a validated tool. ${ }^{47}$ It has been recently demonstrated that QoL in HF patients is driven by HF itself, not by associated comorbidities. ${ }^{48}$ MET-induced improvement in 
myocardial efficiency ${ }^{31}$ suggests that the effect of MET on QoL in HF is rather due to an improvement in $\mathrm{HF}$, not due to improvement in blood glucose control.

Beneficial effects of MET documented in high risk advanced HF population suggest that MET should be more widely used in management of HF. Even in studies with SGLT2 inhibitors in HF patients, a substantial proportion of DM + patients were treated with biguanides (metformin). In DAPA-HF trial, 41.8\% of patients had DM and $51 \%$ of DM + patients were treated by biguanides (predominantly MET) ${ }^{49}$ EMPEROR-Reduced trial reports also a $49.8 \%$ prevalence of DM and although $46.4 \%$ of DM + patients were treated with biguanides. ${ }^{50,51}$ Our data strongly suggest that MET should be a frontline drug for the treatment of diabetic patients with HFrEF. Combination therapy with MET and SGLT2i has been shown safe and efficacious in patients with $\mathrm{DM}^{52}$. Combined therapy of these patients with MET and SGLT2 inhibitors warrants further research.

\section{Limitations}

Our study was performed in a heart center offering a complex cardiovascular program including MCS implantation and HTx. Since this could introduce bias related to the analysis of prognostic value, urgent HTX and MCS implantation were considered adverse outcomes, while the patients receiving non-urgent $\mathrm{HTx}$ were censored as having no adverse outcome on the day of transplantation. ${ }^{13}$ In addition, it was a single-center study with a substantial predominance of males. Our study cohort included patients with advanced HFrEF, the results thus might not be fully applicable to patients with milder HF or to older patients. Data about HF re-hospitalizations were not available in all patients so this endpoint could have not been included in the analysis. The cause of death was not available in all patients, so we were not able to distinguish between cardiovascular and non-cardiovascular mortality. QoL was analyzed only at baseline and is likely a result of a various time of preceding MET therapy; the time of MET treatment before baseline exam or during follow-up is unknown. Data about plasmatic MET concentration are not available; similarly, lactate was not measured. None of the patients was treated by sacubitril-valsartan or SGLT2 inhibitors. Therefore, it is impossible to analyze potentially additional effect of MET and these agents. Only a subset of patients had serial echocardiographic examinations, so it was not possible to analyze the impact of MET-treatment of cardiac reverse remodeling.

\section{Conclusion}

Metformin treatment in advanced HFrEF patients with DM is associated with better quality of life and better outcome by mechanisms beyond the improvement of blood glucose control. Metformin should stay among frontline drugs for the management of HFrEF patients with DM.

\section{Declarations}

\section{Ethics approval and consent to participate}


The ethical committee of the Institute for Clinical and Experimental Medicine-IKEM and Thomayer hospital in Prague approved the study protocol. Written, informed consent for participation in the study was obtained from all the subjects. The study was performed in accordance with the Helsinki Declaration of 1964, and its later amendments.

\section{Consent for publication}

Not applicable. The manuscript does not contain any individual person's data.

\section{Availability of data and materials}

The datasets analyzed during the current study are available from the corresponding author on reasonable request (jan.benes@ikem.cz).

\section{Competing interests}

Josef Kautzner is a member of Advisory Boards for Bayer, Boehringer Ingelheim, Daiichi Sankyo, Biosense Webster, Medtronic and St Jude Medical (Abbott). He has received speaker honoraria from the above-mentioned companies and from Biotronik, Mylan, Pfizer and Pro Med. Petr Jarolim received research support from Abbott Laboratories, Amgen Inc., AstraZeneca LP, Beckman Coulter, Daiichi Sankyo, Inc., GlaxoSmithKline, Merck \& Co., Inc., Roche Diagnostics Corporation, Takeda Global Research and Development Center and Waters Technologies Corporation and speaker honoraria from Roche Diagnostics Corporation. All other authors have no competing interest to declare.

\section{Funding}

This work was supported by Ministry of Health, Czech Republic - conceptual development of research organization („Institute for Clinical and Experimental Medicine - IKEM) [IN 00023001] and by grants nr. 17-28784A and NV19-02-00130, and by NV 19-09-00125.

\section{Authors' contributions}

$\mathrm{JB}, \mathrm{MK}$ and KK participated in the enrollment of patients, performed echocardiography, analyzed the data and wrote the manuscript. PW analyzed the data and revised the manuscript for important intellectual content. JK, JF and PJ performed laboratory analyses and revised the manuscript. $\mathrm{MH}, \mathrm{LH}$ and $\mathrm{EH}$ participated in the enrollment of patients and performed follow-up. TP, JK and VM designed the study, participated in data analysis, interpretation and manuscript preparation. 


\section{Acknowledgements}

Not applicable.

\section{References}

1. Lu, H. C., Parikh, P. P. \& Lorber, D. L. Phenformin-associated lactic acidosis due to imported phenformin. Diabetes care 19, 1449-1450, doi:10.2337/diacare.19.12.1449 (1996).

2. Salpeter, S. R., Greyber, E., Pasternak, G. A. \& Salpeter, E. E. Risk of fatal and nonfatal lactic acidosis with metformin use in type 2 diabetes mellitus. The Cochrane database of systematic reviews 2010, Cd002967, doi:10.1002/14651858.CD002967.pub4 (2010).

3. Eurich, D. T.et al. Comparative safety and effectiveness of metformin in patients with diabetes mellitus and heart failure: systematic review of observational studies involving 34,000 patients. Circulation. Heart failure 6, 395-402, doi:10.1161/circheartfailure.112.000162 (2013).

4. Crowley, M. J.et al. Clinical Outcomes of Metformin Use in Populations With Chronic Kidney Disease, Congestive Heart Failure, or Chronic Liver Disease: A Systematic Review. Annals of internal medicine 166, 191-200, doi:10.7326/m16-1901 (2017).

5. Aguilar, D., Chan, W., Bozkurt, B., Ramasubbu, K. \& Deswal, A. Metformin use and mortality in ambulatory patients with diabetes and heart failure. Circulation. Heart failure 4, 53-58, doi:10.1161/circheartfailure.110.952556 (2011).

6. MacDonald, M. R.et al. Treatment of type 2 diabetes and outcomes in patients with heart failure: a nested case-control study from the U.K. General Practice Research Database. Diabetes care 33, 12131218, doi:10.2337/dc09-2227 (2010).

7. Effect of intensive blood-glucose control with metformin on complications in overweight patients with type 2 diabetes (UKPDS 34). UK Prospective Diabetes Study (UKPDS) Group. Lancet 352, 854865 (1998).

8. Shah, D. D., Fonarow, G. C. \& Horwich, T. B. Metformin therapy and outcomes in patients with advanced systolic heart failure and diabetes. Journal of cardiac failure 16, 200-206, doi:10.1016/j.cardfail.2009.10.022 (2010).

9. Cosentino, F.et al. 2019 ESC Guidelines on diabetes, pre-diabetes, and cardiovascular diseases developed in collaboration with the EASD. European heart journal 41, 255-323, doi:10.1093/eurheartj/ehz486 (2020).

10. Lang, R. M.et al. Recommendations for chamber quantification. European journal of echocardiography : the journal of the Working Group on Echocardiography of the European Society of Cardiology 7, 79-108, doi:10.1016/j.euje.2005.12.014 (2006). 
11. Kaul, S., Tei, C., Hopkins, J. M. \& Shah, P. M. Assessment of right ventricular function using twodimensional echocardiography. American heart journal 107, 526-531, doi:10.1016/00028703(84)90095-4 (1984).

12. Meluzín, J.et al. Pulsed Doppler tissue imaging of the velocity of tricuspid annular systolic motion; a new, rapid, and non-invasive method of evaluating right ventricular systolic function. European heart journal 22, 340-348, doi:10.1053/euhj.2000.2296 (2001).

13. Aaronson, K. D.et al. Development and prospective validation of a clinical index to predict survival in ambulatory patients referred for cardiac transplant evaluation. Circulation 95, 2660-2667, doi:10.1161/01.cir.95.12.2660 (1997).

14. Matthews, D. R.et al. Homeostasis model assessment: insulin resistance and beta-cell function from fasting plasma glucose and insulin concentrations in man. Diabetologia 28, 412-419, doi:10.1007/bf00280883 (1985).

15. Inzucchi, S. E., Masoudi, F. A. \& McGuire, D. K. Metformin in heart failure. Diabetes care 30, e129, doi:10.2337/dc07-1686 (2007).

16. Tseng, C. H. Metformin Use Is Associated With a Lower Risk of Hospitalization for Heart Failure in Patients With Type 2 Diabetes Mellitus: a Retrospective Cohort Analysis. J Am Heart Assoc 8, e011640, doi:10.1161/jaha.118.011640 (2019).

17. Bergmark, B. A.et al. Metformin Use and Clinical Outcomes Among Patients With Diabetes Mellitus With or Without Heart Failure or Kidney Dysfunction: Observations From the SAVOR-TIMI 53 Trial. Circulation 140, 1004-1014, doi:10.1161/circulationaha.119.040144 (2019).

18. Inzucchi, S. E.et al. Insulin-sensitizing antihyperglycemic drugs and mortality after acute myocardial infarction: insights from the National Heart Care Project. Diabetes care 28, 1680-1689, doi:10.2337/diacare.28.7.1680 (2005).

19. Masoudi, F. A.et al. Thiazolidinediones, metformin, and outcomes in older patients with diabetes and heart failure: an observational study. Circulation 111, 583-590, doi:10.1161/01.cir.0000154542.13412.b1 (2005).

20. Eurich, D. T., Majumdar, S. R., McAlister, F. A., Tsuyuki, R. T. \& Johnson, J. A. Improved clinical outcomes associated with metformin in patients with diabetes and heart failure. Diabetes care $\mathbf{2 8}$, 2345-2351, doi:10.2337/diacare.28.10.2345 (2005).

21. Evans, J. M.et al. Effect of Metformin on mortality in patients with heart failure and type 2 diabetes mellitus. The American journal of cardiology 106, 1006-1010, doi:10.1016/j.amjcard.2010.05.031 (2010).

22. Roussel, R.et al. Metformin use and mortality among patients with diabetes and atherothrombosis. Archives of internal medicine 170, 1892-1899, doi:10.1001/archinternmed.2010.409 (2010).

23. Andersson, C.et al. Metformin treatment is associated with a low risk of mortality in diabetic patients with heart failure: a retrospective nationwide cohort study. Diabetologia 53, 2546-2553, doi:10.1007/s00125-010-1906-6 (2010). 
24. Romero, S. P.et al. Metformin therapy and prognosis of patients with heart failure and new-onset diabetes mellitus. A propensity-matched study in the community. International journal of cardiology 166, 404-412, doi:10.1016/j.ijcard.2011.10.141 (2013).

25. Tinetti, M. E., McAvay, G., Trentalange, M., Cohen, A. B. \& Allore, H. G. Association between guideline recommended drugs and death in older adults with multiple chronic conditions: population based cohort study. BMJ (Clinical research ed.) 351, h4984, doi:10.1136/bmj.h4984 (2015).

26. Weir, D. L., McAlister, F. A., Senthilselvan, A., Minhas-Sandhu, J. K. \& Eurich, D. T. Sitagliptin use in patients with diabetes and heart failure: a population-based retrospective cohort study. JACC. Heart failure 2, 573-582, doi:10.1016/j.jchf.2014.04.005 (2014).

27. Eurich, D. T.et al. Metformin treatment in diabetes and heart failure: when academic equipoise meets clinical reality. Trials 10, 12, doi:10.1186/1745-6215-10-12 (2009).

28. Owen, M. R., Doran, E. \& Halestrap, A. P. Evidence that metformin exerts its anti-diabetic effects through inhibition of complex 1 of the mitochondrial respiratory chain. The Biochemical journal $\mathbf{3 4 8}$ Pt 3, 607-614 (2000).

29. El-Mir, M. Y.et al. Dimethylbiguanide inhibits cell respiration via an indirect effect targeted on the respiratory chain complex I. The Journal of biological chemistry $275,223-228$, doi:10.1074/jbc.275.1.223 (2000).

30. Kanamori, H.et al. Metformin Enhances Autophagy and Provides Cardioprotection in $\delta$-Sarcoglycan Deficiency-Induced Dilated Cardiomyopathy. Circulation. Heart failure 12, e005418, doi:10.1161/circheartfailure.118.005418 (2019).

31. Larsen, A. H.et al. A randomised, double-blind, placebo-controlled trial of metformin on myocardial efficiency in insulin-resistant chronic heart failure patients without diabetes. European journal of heart failure 22, 1628-1637, doi:10.1002/ejhf.1656 (2020).

32. Wu, H.et al. Metformin alters the gut microbiome of individuals with treatment-naive type 2 diabetes, contributing to the therapeutic effects of the drug. Nature medicine $23,850-858$, doi:10.1038/nm.4345 (2017).

33. He, K.et al. The effect of metformin therapy on incidence and prognosis in prostate cancer: $A$ systematic review and meta-analysis. Scientific reports 9 , 2218, doi:10.1038/s41598-018-38285-w (2019).

34. Anselmino, L. E.et al. Repositioning metformin and propranolol for colorectal and triple negative breast cancers treatment. Scientific reports 11, 8091, doi:10.1038/s41598-021-87525-z (2021).

35. Meijers, W. C.et al. Heart Failure Stimulates Tumor Growth by Circulating Factors. Circulation 138, 678-691, doi:10.1161/circulationaha.117.030816 (2018).

36. Banke, A. et al. Incidence of cancer in patients with chronic heart failure: a long-term follow-up study. European journal of heart failure 18, 260-266, doi:10.1002/ ejhf.472 (2016).

37. Holman, R. R., Paul, S. K., Bethel, M. A., Matthews, D. R. \& Neil, H. A. 10-year follow-up of intensive glucose control in type 2 diabetes. The New England journal of medicine 359, 1577-1589, doi:10.1056/NEJMoa0806470 (2008). 
38. Cameron, A. R.et al. Anti-Inflammatory Effects of Metformin Irrespective of Diabetes Status. Circulation research 119, 652-665, doi:10.1161/circresaha.116.308445 (2016).

39. Mohan, M.et al. A randomized controlled trial of metformin on left ventricular hypertrophy in patients with coronary artery disease without diabetes: the MET-REMODEL trial. European heart journal 40, 3409-3417, doi:10.1093/eurheartj/ehz203 (2019).

40. Santos-Gallego, C. G.et al. Empagliflozin Ameliorates Adverse Left Ventricular Remodeling in Nondiabetic Heart Failure by Enhancing Myocardial Energetics. Journal of the American College of Cardiology 73, 1931-1944, doi:10.1016/j.jacc.2019.01.056 (2019).

41. Coll, A. P.et al. GDF15 mediates the effects of metformin on body weight and energy balance. Nature 578, 444-448, doi:10.1038/s41586-019-1911-y (2020).

42. Benes, J.et al. The Role of GDF-15 in Heart Failure Patients With Chronic Kidney Disease. The Canadian journal of cardiology 35, 462-470, doi:10.1016/j.cjca.2018.12.027 (2019).

43. Monzo, L.et al. Myocardial ketone body utilization in patients with heart failure: The impact of oral ketone ester. Metabolism: clinical and experimental 115, 154452, doi:10.1016/j.metabol.2020.154452 (2021).

44. Nielsen, R.et al. Cardiovascular Effects of Treatment With the Ketone Body 3-Hydroxybutyrate in Chronic Heart Failure Patients. Circulation 139, 2129-2141, doi:10.1161/circulationaha.118.036459 (2019).

45. Konopka, A. R.et al. Hyperglucagonemia Mitigates the Effect of Metformin on Glucose Production in Prediabetes. Cell reports 23, 2532, doi:10.1016/j.celrep.2018.05.027 (2018).

46. Landstedt-Hallin, L., Englund, A., Adamson, U. \& Lins, P. E. Increased QT dispersion during hypoglycaemia in patients with type 2 diabetes mellitus. Journal of internal medicine 246, 299-307, doi:10.1046/j.1365-2796.1999.00528.x (1999).

47. Rector, T. S., Kubo, S. H. \& Cohn, J. N. Validity of the Minnesota Living with Heart Failure questionnaire as a measure of therapeutic response to enalapril or placebo. The American journal of cardiology 71, 1106-1107, doi:10.1016/0002-9149(93)90582-w (1993).

48. Benes, J.et al. The effect of three major co-morbidities on quality of life and outcome of patients with heart failure with reduced ejection fraction. ESC heart failure, doi:10.1002/ehf2.13227 (2021).

49. McMurray, J. J. V.et al. Dapagliflozin in Patients with Heart Failure and Reduced Ejection Fraction. The New England journal of medicine 381, 1995-2008, doi:10.1056/NEJMoa1911303 (2019).

50. Packer, M.et al. Cardiovascular and Renal Outcomes with Empagliflozin in Heart Failure. The New England journal of medicine 383, 1413-1424, doi:10.1056/NEJMoa2022190 (2020).

51. Anker, S. D.et al. Effect of Empagliflozin on Cardiovascular and Renal Outcomes in Patients With Heart Failure by Baseline Diabetes Status: Results From the EMPEROR-Reduced Trial. Circulation 143, 337-349, doi:10.1161/circulationaha.120.051824 (2021).

52. Gebrie, D., Getnet, D. \& Manyazewal, T. Cardiovascular safety and efficacy of metformin-SGLT2i versus metformin-sulfonylureas in type 2 diabetes: systematic review and meta-analysis of randomized controlled trials. Scientific reports 11, 137, doi:10.1038/s41598-020-80603-8 (2021). 


\section{Tables}

Table 1

Patients characteristics

Page 16/26 


\begin{tabular}{|c|c|c|c|c|c|c|c|}
\hline & $\begin{array}{l}\text { Whole } \\
\text { cohort } \\
(n= \\
847)\end{array}$ & $\begin{array}{l}\text { Non-DM } \\
(n= \\
467)\end{array}$ & $\begin{array}{c}\text { DM } \\
(n= \\
380)\end{array}$ & $\begin{array}{l}\text { P } \\
\text { (non- } \\
\text { DM vs. } \\
\text { DM) }\end{array}$ & $\begin{array}{l}\text { DM } \\
\text { MET- } \\
\text { free } \\
(n= \\
290)\end{array}$ & $\begin{array}{l}\text { DM } \\
\text { MET- } \\
\text { treated } \\
(n=87)\end{array}$ & $\begin{array}{l}\mathrm{P} \\
\text { (MET- } \\
\text { free vs. } \\
\text { MET- } \\
\text { treated) }\end{array}$ \\
\hline Age (years) & $\begin{array}{l}57.40 \pm \\
11.28\end{array}$ & $\begin{array}{l}55.03 \pm \\
11.94\end{array}$ & $\begin{array}{l}60.31 \pm \\
9.65\end{array}$ & $<0.0001$ & $\begin{array}{l}60.14 \pm \\
9.63\end{array}$ & $\begin{array}{l}60.92 \pm \\
9.85\end{array}$ & 0.51 \\
\hline Males (\%) & 82.8 & 81.6 & 84.2 & 0.31 & 83.5 & 86.2 & 0.53 \\
\hline $\begin{array}{l}\text { HF etiology } \\
(\% \text { CAD) }\end{array}$ & 50.2 & 41.6 & 60.8 & $<0.0001$ & 59.4 & 65.1 & 0.34 \\
\hline $\mathrm{BMI}\left(\mathrm{kg} \cdot \mathrm{m}^{-2}\right)$ & $\begin{array}{l}27.82 \pm \\
5.09\end{array}$ & $\begin{array}{l}26.94 \pm \\
4.55\end{array}$ & $\begin{array}{l}28.9 \pm \\
5.50\end{array}$ & $<0.0001$ & $\begin{array}{l}28.27 \pm \\
5.31\end{array}$ & $\begin{array}{l}30.98 \pm \\
5.61\end{array}$ & $<0.0001$ \\
\hline NYHA $(2-4, \%)$ & $\begin{array}{l}32.2 / \\
60.3 / \\
7.4\end{array}$ & $\begin{array}{l}35.1 / \\
58.9 / \\
6.0\end{array}$ & $\begin{array}{l}28.7 / \\
62.1 / \\
9.2\end{array}$ & 0.11 & $\begin{array}{l}25.5 / \\
63.5 / \\
11.0\end{array}$ & $\begin{array}{l}40.2 / \\
56.3 / \\
3.5\end{array}$ & 0.02 \\
\hline $\operatorname{BNP}\left(n g . f^{-1}\right)$ & $\begin{array}{l}466 \\
(208 ; \\
1077)\end{array}$ & $\begin{array}{l}381 \\
(162 ; \\
948)\end{array}$ & $\begin{array}{l}613 \\
(264 ; \\
1187)\end{array}$ & $<0.0001$ & $\begin{array}{l}642 \\
(334 ; \\
1354)\end{array}$ & $\begin{array}{l}400 \\
(148 ; \\
920)\end{array}$ & 0.0002 \\
\hline Hemoglobin $\left(g . \digamma^{-1}\right)$ & $\begin{array}{l}140.85 \pm \\
18.18\end{array}$ & $\begin{array}{l}142.00 \pm \\
18.36\end{array}$ & $\begin{array}{l}139.49 \pm \\
17.90\end{array}$ & 0.049 & $\begin{array}{l}140.09 \pm \\
18.13\end{array}$ & $\begin{array}{l}138.00 \pm \\
16.39\end{array}$ & 0.34 \\
\hline $\begin{array}{l}\text { eGFR } \\
\left(\text { ml.min }^{-1} \cdot 1.73 m^{-2}\right)\end{array}$ & $\begin{array}{l}68.91 \pm \\
22.50\end{array}$ & $\begin{array}{l}72.55 \pm \\
22.55\end{array}$ & $\begin{array}{l}64.59 \pm \\
21.69\end{array}$ & $<0.0001$ & $\begin{array}{l}63.34 \pm \\
22.12\end{array}$ & $\begin{array}{l}69.26 \pm \\
19.76\end{array}$ & 0.03 \\
\hline $\operatorname{CRP}\left(m g . \digamma^{-1}\right)$ & $\begin{array}{l}4.5(1.9 ; \\
9.9)\end{array}$ & $\begin{array}{l}3.5(1.5 \\
8.1)\end{array}$ & $\begin{array}{l}5.5(2.5 ; \\
11.4)\end{array}$ & $<0.0001$ & $\begin{array}{l}5.5(2.9 ; \\
11.3)\end{array}$ & $\begin{array}{l}5.3(2.1 ; \\
13.2)\end{array}$ & 0.70 \\
\hline \multicolumn{8}{|c|}{ Diabetes and metabolism } \\
\hline $\begin{array}{l}\text { Glucagon } \\
\left(m / U \cdot m r^{-1}\right)\end{array}$ & $\begin{array}{l}97(77 ; \\
125)\end{array}$ & $\begin{array}{l}90.8 \\
\text { (73.83; } \\
116.2)\end{array}$ & $\begin{array}{l}105.7 \\
(82.5 ; \\
132.8)\end{array}$ & $<0.0001$ & $\begin{array}{l}102.35 \\
(80.35 \\
128.73)\end{array}$ & $\begin{array}{c}116.30 \\
(92.10 \\
145.70)\end{array}$ & 0.015 \\
\hline $\begin{array}{l}\text { C-peptid } \\
\left(n m o l . L^{-1}\right)\end{array}$ & $\begin{array}{l}1.38 \\
(0.958 ; \\
1.942)\end{array}$ & $\begin{array}{l}1.27 \\
(0.92 ; \\
1.76)\end{array}$ & $\begin{array}{l}1.52 \\
(1.03 ; \\
2.16)\end{array}$ & $<0.0001$ & $\begin{array}{l}1.50 \\
(1.02 ; \\
2.12)\end{array}$ & $\begin{array}{l}1.56 \\
(1.08 ; \\
2.26)\end{array}$ & 0.90 \\
\hline $\begin{array}{l}\text { Free fatty acids } \\
\left(m m o l . L^{-1}\right)\end{array}$ & $\begin{array}{l}0.53 \\
(0.37 \\
0.72)\end{array}$ & $\begin{array}{l}0.49 \\
(0.35 \\
0.69)\end{array}$ & $\begin{array}{l}0.59 \\
(0.40 \\
0.79)\end{array}$ & 0.0008 & $\begin{array}{l}0.61 \\
(0.39 \\
0.80)\end{array}$ & $\begin{array}{l}0.57 \\
(0.42 \\
0.79)\end{array}$ & 0.74 \\
\hline \multicolumn{8}{|l|}{ Biomarkers } \\
\hline $\begin{array}{l}\mathrm{Hs}-\mathrm{TnT}^{\&} \\
\left(n g . I^{-1}\right)\end{array}$ & $\begin{array}{l}23.86 \\
(14.46 ; \\
40.72)\end{array}$ & $\begin{array}{l}20.05 \\
(11.98 \\
33.41)\end{array}$ & $\begin{array}{l}28.18 \\
(18.71 ; \\
49.03)\end{array}$ & $<0.0001$ & $\begin{array}{l}29.3 \\
(18.8 \\
49.2)\end{array}$ & $\begin{array}{l}25.3 \\
(17.6 \\
43.1)\end{array}$ & 0.49 \\
\hline
\end{tabular}


Cardiac morphology and function

\begin{tabular}{|c|c|c|c|c|c|c|c|}
\hline $\mathrm{SBP}(m m H g)$ & $\begin{array}{l}116.33 \pm \\
19.10\end{array}$ & $\begin{array}{l}115.3 \pm \\
19.2\end{array}$ & $\begin{array}{l}117.6 \pm \\
18.9\end{array}$ & 0.07 & $\begin{array}{l}116.08 \pm \\
18.89\end{array}$ & $\begin{array}{l}122.78 \pm \\
18.00\end{array}$ & 0.004 \\
\hline Heart rate $\left(\min ^{-1}\right)$ & $\begin{array}{l}75.72 \pm \\
14.54\end{array}$ & $\begin{array}{l}74.22 \pm \\
14.77\end{array}$ & $\begin{array}{l}77.55 \pm \\
14.07\end{array}$ & 0.002 & $\begin{array}{l}77.66 \pm \\
14.26\end{array}$ & $\begin{array}{l}77.43 \pm \\
13.61\end{array}$ & 0.90 \\
\hline LVEDD $(\mathrm{mm})$ & $\begin{array}{l}69.41 \pm \\
9.11\end{array}$ & $\begin{array}{l}69.82 \pm \\
9.72\end{array}$ & $\begin{array}{l}68.90 \pm \\
8.28\end{array}$ & 0.14 & $\begin{array}{l}69.04 \pm \\
8.47\end{array}$ & $\begin{array}{l}68.31 \pm \\
7.68\end{array}$ & 0.47 \\
\hline LVEF (\%) & $\begin{array}{l}23.59 \pm \\
5.80\end{array}$ & $\begin{array}{l}23.57 \pm \\
5.80\end{array}$ & $\begin{array}{l}23.63 \pm \\
5.79\end{array}$ & 0.88 & $\begin{array}{l}23.05 \pm \\
5.82\end{array}$ & $\begin{array}{l}25.60 \pm \\
5.30\end{array}$ & 0.0003 \\
\hline RVD1 (mm) & $\begin{array}{l}40.62 \pm \\
7.94\end{array}$ & $\begin{array}{l}39.64 \pm \\
8.11\end{array}$ & $\begin{array}{l}41.81 \pm \\
7.58\end{array}$ & $<0.0001$ & $\begin{array}{l}41.93 \pm \\
7.81\end{array}$ & $\begin{array}{l}41.40 \pm \\
6.89\end{array}$ & 0.57 \\
\hline $\begin{array}{l}\text { RV dysfunction } \\
\text { grade }(0-3, \%)\end{array}$ & $\begin{array}{l}32.3 \\
22.8 / \\
33.5 / \\
11.4\end{array}$ & $\begin{array}{c}38.5 / \\
23.8 / \\
28.6 / \\
9.1\end{array}$ & $\begin{array}{l}24.7 / \\
21.6 / \\
39.5 / \\
14.2\end{array}$ & $<0.0001$ & $\begin{array}{c}19.9 / \\
21.4 / \\
42.8 / \\
15.9\end{array}$ & $\begin{array}{l}42.2 / \\
21.7 / \\
27.7 / \\
8.4\end{array}$ & 0.002 \\
\hline $\begin{array}{l}\text { Mitral regurgitation } \\
(1-3, \%)\end{array}$ & $\begin{array}{l}25.2 / \\
40.5 / \\
34.3\end{array}$ & $\begin{array}{l}27.0 / \\
40.3 / \\
32.7\end{array}$ & $\begin{array}{l}22.9 / \\
40.8 / \\
36.3\end{array}$ & 0.32 & $\begin{array}{l}18.3 / \\
44.1 / \\
37.6\end{array}$ & $\begin{array}{l}39.1 / \\
28.7 / \\
32.2\end{array}$ & 0.0004 \\
\hline $\begin{array}{l}\text { Tricuspid } \\
\text { regurgitation (1-3, } \\
\%)\end{array}$ & $\begin{array}{l}44.6 / \\
39.0 / \\
16.3\end{array}$ & $\begin{array}{l}48.9 / \\
37.4 / \\
13.7\end{array}$ & $\begin{array}{l}39.4 / \\
41.0 / \\
19.6\end{array}$ & 0.001 & $\begin{array}{l}34.0 / \\
44.5 / \\
21.5\end{array}$ & $\begin{array}{l}57.5 / \\
31.0 / \\
11.5\end{array}$ & 0.0004 \\
\hline $\begin{array}{l}\text { Estimated systolic } \\
\text { pulmonary pressure } \\
(\mathrm{mmHg})\end{array}$ & $\begin{array}{l}45.11 \pm \\
13.65\end{array}$ & $\begin{array}{l}43.46 \pm \\
13.93\end{array}$ & $\begin{array}{l}46.98 \pm \\
13.10\end{array}$ & 0.002 & $\begin{array}{l}46.97 \pm \\
12.95\end{array}$ & $\begin{array}{l}47.60 \pm \\
13.05\end{array}$ & 0.74 \\
\hline IVC (mm) & $\begin{array}{l}19.55 \pm \\
5.74\end{array}$ & $\begin{array}{l}18.93 \pm \\
5.58\end{array}$ & $\begin{array}{l}20.31 \pm \\
5.86\end{array}$ & 0.0006 & $\begin{array}{l}20.45 \pm \\
5.81\end{array}$ & $\begin{array}{l}19.54 \pm \\
5.36\end{array}$ & 0.21 \\
\hline
\end{tabular}

\section{Quality of life}

MLHFQ sum

$44(26$

$43(24 ; \quad 44(28 ;$

0.25

61)

48 (30;

62)

36 (16;

0.002

60)

59)

22 (12;

28)

0.59

$23(14 ; \quad 17(10$;

29)

24)

MLHFQ emotional

$6(2 ; 11)$

$6(1 ; 12)$

$6(2 ; 11)$

0.86

$6(3 ; 12)$

$5(1 ; 10)$

0.09

\section{Hemodynamics $^{\Delta}$}

\begin{tabular}{|c|c|c|c|c|c|c|c|}
\hline $\begin{array}{l}\text { RA pressure } \\
(\mathrm{mmHg})\end{array}$ & $9(6 ; 13)$ & $8(5 ; 12)$ & $\begin{array}{l}10(6 \\
16)\end{array}$ & 0.0009 & $\begin{array}{l}10(6 ; \\
16)\end{array}$ & $9(7 ; 14)$ & 0.56 \\
\hline $\begin{array}{l}\text { Systolic PA } \\
\text { pressure }(m m H g)\end{array}$ & $\begin{array}{l}53(38 \\
65)\end{array}$ & $\begin{array}{l}47(34 \\
62)\end{array}$ & $\begin{array}{l}57(44 \\
68)\end{array}$ & $<0.0001$ & $\begin{array}{l}57(44 \\
69)\end{array}$ & $\begin{array}{l}60(45 ; \\
68)\end{array}$ & 0.89 \\
\hline
\end{tabular}




\begin{tabular}{|c|c|c|c|c|c|c|c|}
\hline $\begin{array}{l}\text { Diastolic PA } \\
\text { pressure }(\mathrm{mmHg})\end{array}$ & $\begin{array}{l}24(18 ; \\
31)\end{array}$ & $\begin{array}{l}22(16 ; \\
29.5)\end{array}$ & $\begin{array}{l}27(20 \\
32)\end{array}$ & 0.005 & $\begin{array}{l}27 \\
(19.5 ; \\
32)\end{array}$ & $\begin{array}{l}26.5 \\
(19.75 ; \\
32.25)\end{array}$ & 0.92 \\
\hline $\begin{array}{l}\text { Mean PA pressure } \\
(\mathrm{mmHg})\end{array}$ & $\begin{array}{l}35(26 \\
43)\end{array}$ & $\begin{array}{l}32(23 ; \\
42)\end{array}$ & $\begin{array}{l}37(30 ; \\
45)\end{array}$ & 0.0003 & $\begin{array}{l}37(30 \\
45)\end{array}$ & $\begin{array}{l}38(32 ; \\
44)\end{array}$ & 0.99 \\
\hline PCWP $(m m H g)$ & $\begin{array}{l}24(17 \\
29)\end{array}$ & $\begin{array}{l}23(16 ; \\
28)\end{array}$ & $\begin{array}{l}25(19 ; \\
30)\end{array}$ & 0.02 & $\begin{array}{l}24.5 \\
(19 ; 30\end{array}$ & $\begin{array}{l}25(16 ; \\
31)\end{array}$ & 0.73 \\
\hline $\mathrm{Cl}\left(1 / \mathrm{min} / 1.73 \mathrm{~m}^{2}\right)$ & $\begin{array}{l}1.84 \\
(1.58 \\
2.15)\end{array}$ & $\begin{array}{l}1.90 \\
(1.59 ; \\
2.18)\end{array}$ & $\begin{array}{l}1.80 \\
(1.55 ; \\
2.14)\end{array}$ & 0.14 & $\begin{array}{l}1.75 \\
(1.51 ; \\
2.13)\end{array}$ & $\begin{array}{l}1.96 \\
(1.73 ; \\
2.32)\end{array}$ & 0.06 \\
\hline \multicolumn{8}{|l|}{ Therapy } \\
\hline ACEi/ARB (\%) & 78.65 & 79.83 & 77.31 & 0.37 & 77.51 & 79.31 & 0.72 \\
\hline BB (\%) & 87.66 & 88.20 & 87.07 & 0.62 & 88.58 & 82.76 & 0.17 \\
\hline MRA (\%) & 76.99 & 75.32 & 78.89 & 0.22 & 79.93 & 75.86 & 0.42 \\
\hline $\begin{array}{l}\text { Furosemide daily } \\
\text { dose }(m g)\end{array}$ & $\begin{array}{l}80(40 ; \\
125)\end{array}$ & $\begin{array}{l}60(40 ; \\
120)\end{array}$ & $\begin{array}{l}80(40 ; \\
125)\end{array}$ & $<0.0001$ & $\begin{array}{l}80(40 \\
131.25)\end{array}$ & $\begin{array}{l}60(40 ; \\
125)\end{array}$ & 0.03 \\
\hline ICD any (\%) & 59.4 & 57.8 & 61.4 & 0.29 & 61.70 & 61.45 & 0.97 \\
\hline CRT any (\%) & 32.0 & 31.5 & 32.6 & 0.73 & 35.11 & 24.10 & 0.06 \\
\hline Amiodarone (\%) & 18.3 & 17.9 & 18.8 & 0.73 & 19.66 & 16.09 & 0.45 \\
\hline Insulin (\%) & - & - & 28.4 & - & 30.34 & 22.99 & 0.18 \\
\hline Insulin daily dose & - & - & $\begin{array}{l}48(31 ; \\
66)^{*}\end{array}$ & - & $\begin{array}{l}46(31 ; \\
63.5)\end{array}$ & $\begin{array}{l}54.5 \\
(31.5 \\
80)\end{array}$ & 0.29 \\
\hline SU derivatives (\%) & - & - & 17.6 & - & 15.17 & 26.44 & 0.02 \\
\hline $\begin{array}{l}\text { DPP-IV inhibitors } \\
\text { (\%) }\end{array}$ & - & - & 6.8 & - & 4.83 & 13.79 & 0.007 \\
\hline
\end{tabular}

\section{Outcome}

\begin{tabular}{llllllll} 
Death (\%) & 324 & 134 & 190 & - & 152 & 37 & - \\
& $(38.3 \%)$ & $(28.7 \%)$ & $(50.0 \%)$ & & $(52.4 \%)$ & $(42.5 \%)$ & \\
Urg. HTx (\%) & 107 & 63 & 44 & - & 39 & 4 & -- \\
& $(12.6 \%)$ & $(13.5 \%)$ & $(11.6 \%)$ & & $(13.5 \%)$ & $(4.6 \%)$ & \\
\hline Norm. HTx (\%) & 35 & 23 & 12 & - & 10 & 2 & - \\
& $(4.1 \%)$ & $(4.9 \%)$ & $(3.2 \%)$ & & $(3.5 \%)$ & $(2.3 \%)$ & \\
& & & & & & &
\end{tabular}


MCSi (\%)

83

$(9.8 \%)$

48

$(10.3 \%)$

35

$(9.2 \%)$

28

$(9.7 \%)$

6

Data are shown as mean \pm SD or median with IQRs.

$\&$ available in 450 patients only. $\Delta$ available in 385 patients only. * calculated for only 108 patients treated with insulin. Information about DM treatment was missing in 3 patients.

\section{Table 2}

\section{Metformin and outcome, Cox proportional hazard analysis}

\begin{tabular}{|c|c|c|c|c|}
\hline & & $\mathrm{HR}$ & $95 \% \mathrm{Cl}$ & $\mathrm{p}$ \\
\hline Model 1 & MET (present vs. absent) & 0.57 & $0.41-0.78$ & 0.0003 \\
\hline \multirow[t]{2}{*}{ Model 2} & MET (present vs. absent) & 0.63 & $0.45-0.87$ & 0.004 \\
\hline & $\mathrm{BMI}\left(k g \cdot m^{-2}\right)$ & 0.97 & $0.94-0.99$ & 0.005 \\
\hline \multirow[t]{3}{*}{ Model 3} & MET (present vs. absent) & 0.64 & $0.46-0.88$ & 0.007 \\
\hline & $\mathrm{BMI}\left(\mathrm{kg} \cdot \mathrm{m}^{-2}\right)$ & 0.97 & $0.94-0.99$ & 0.01 \\
\hline & eGFR $\left(m l \cdot m^{-1} n^{-1} \cdot 1 \cdot 73 m^{-2}\right)$ & 0.995 & 0.989- 1.0006 & 0.08 \\
\hline \multirow[t]{4}{*}{ Model 4} & MET (present vs. absent) & 0.70 & $0.50-0.98$ & 0.035 \\
\hline & $\mathrm{BNP}\left(n g . L^{-1}\right)$ & 1.00056 & $1.0004-1.0007$ & $<0.0001$ \\
\hline & $\mathrm{BMI}\left(k g \cdot m^{-2} 7\right.$ & 0.99 & $0.97-1.018$ & 0.51 \\
\hline & eGFR $\left(m I . m i n-1.1 .73 m^{-2}\right)$ & 0.996 & $0.991-1.002$ & 0.24 \\
\hline
\end{tabular}

\section{Figures}


1332 pts. with HF electively hospitalized at IKEM between 2008-2016

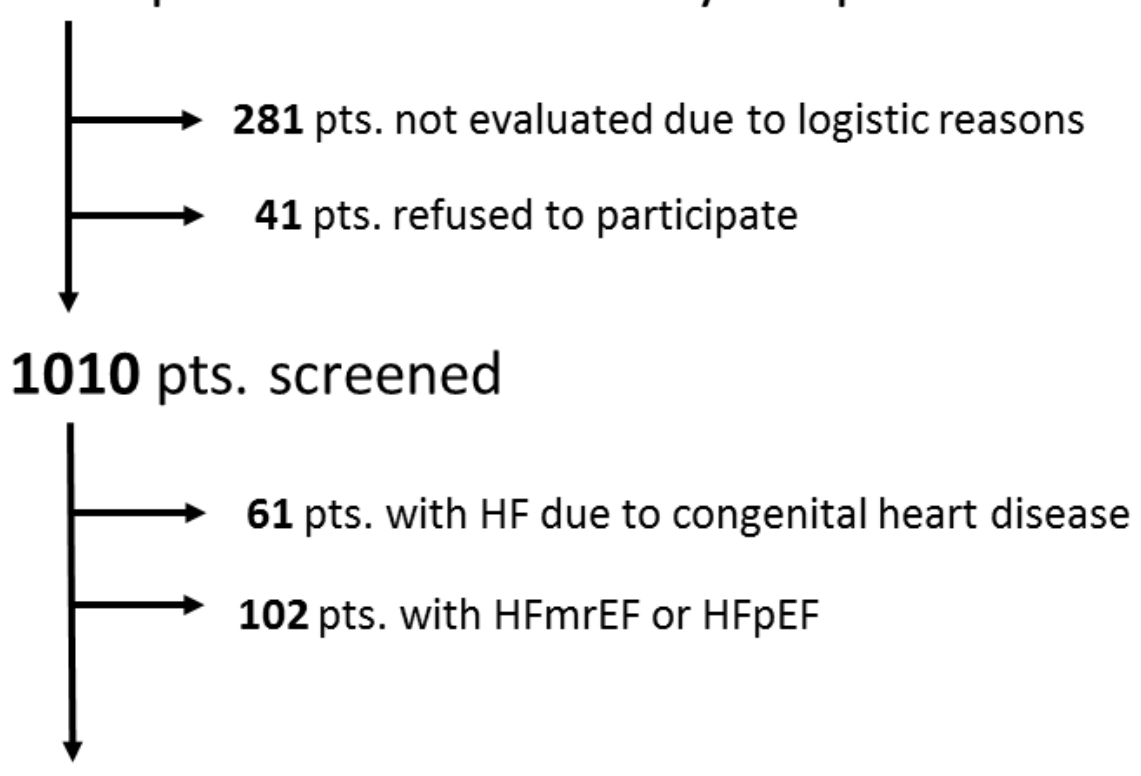

847 pts. enrolled

Figure 1

Consolidated Standards of Reporting Trials (CONSORT) diagram. 


\section{DM treatment}
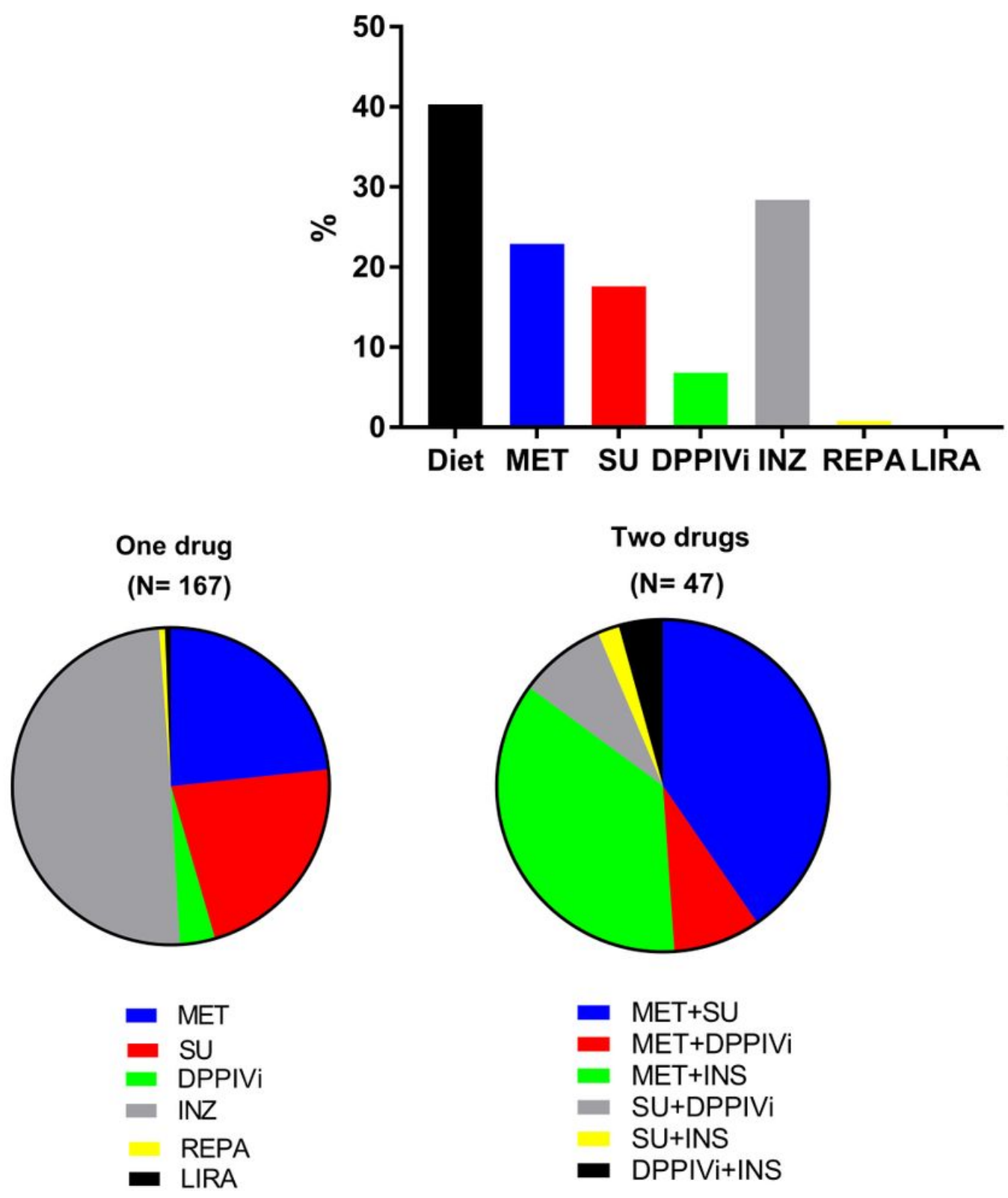

Three drugs

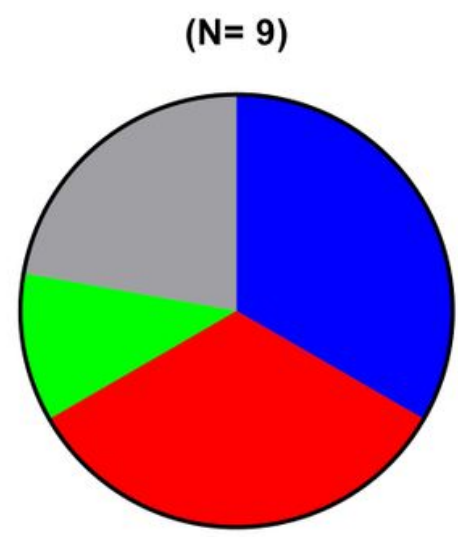

- MET+DPPIVi+SU

- MET+DPPIVi+INS

- MET+DPPIVi+REPA

- SU+DPPIVi+INS

Figure 2

DM treatment. The information about DM treatment was missing in 3 patients. 
Glucose

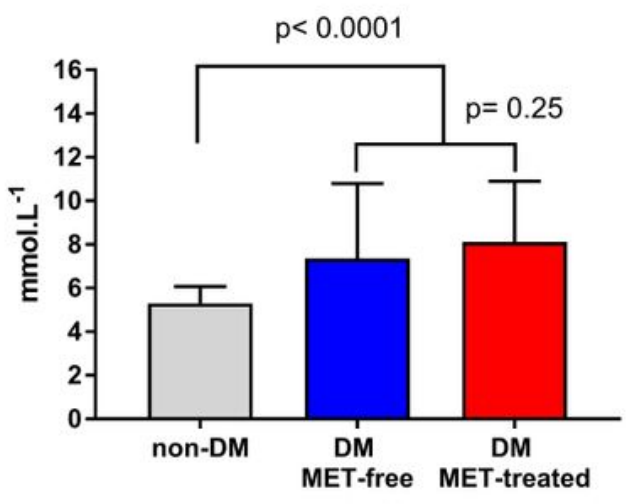

HOMA-IR

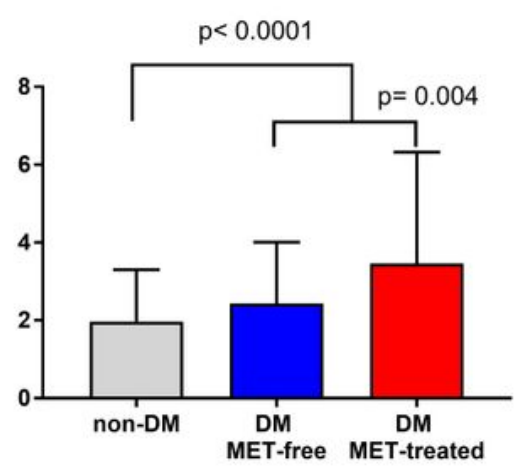

GDF-15

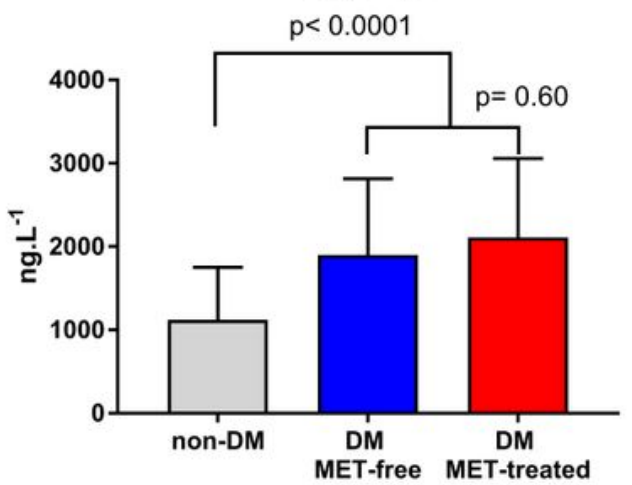

Hb1Ac

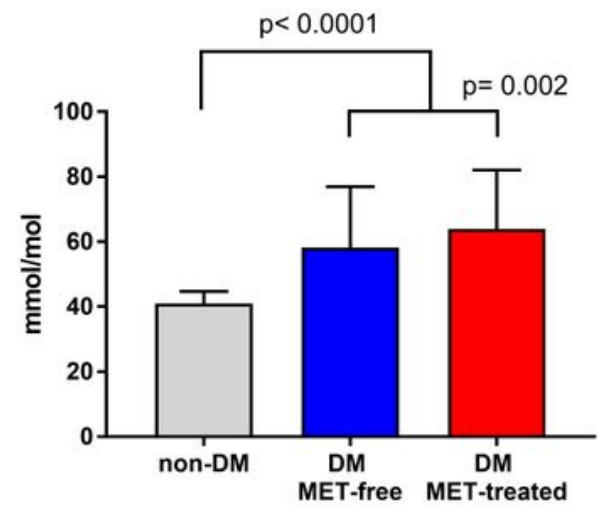

Glucagon

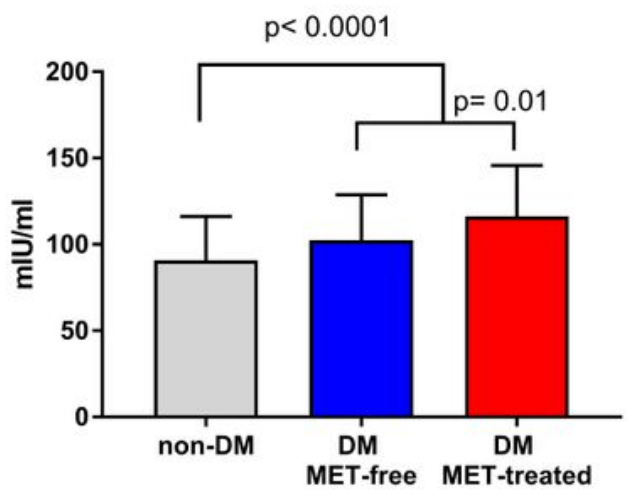

3-hydroxybutyrate

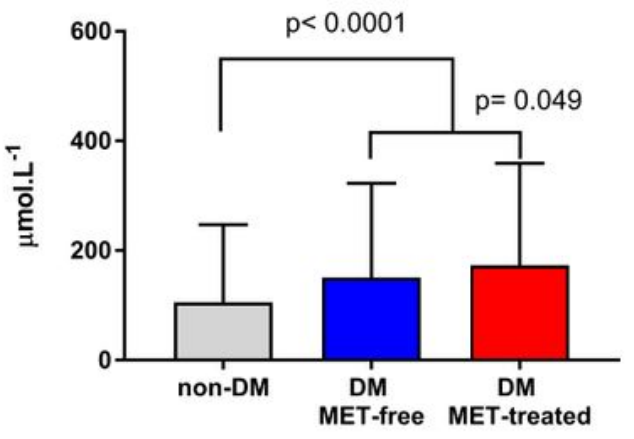

\section{Figure 3}

Metabolic profile

For Glucose and $\mathrm{Hb} 1 \mathrm{Ac}$, data are shown as mean $\pm \mathrm{SD}$, for HOMA-IR, Glucagon, GDF-15 and 3-hydroxybutyrate as median \pm IQRs. 

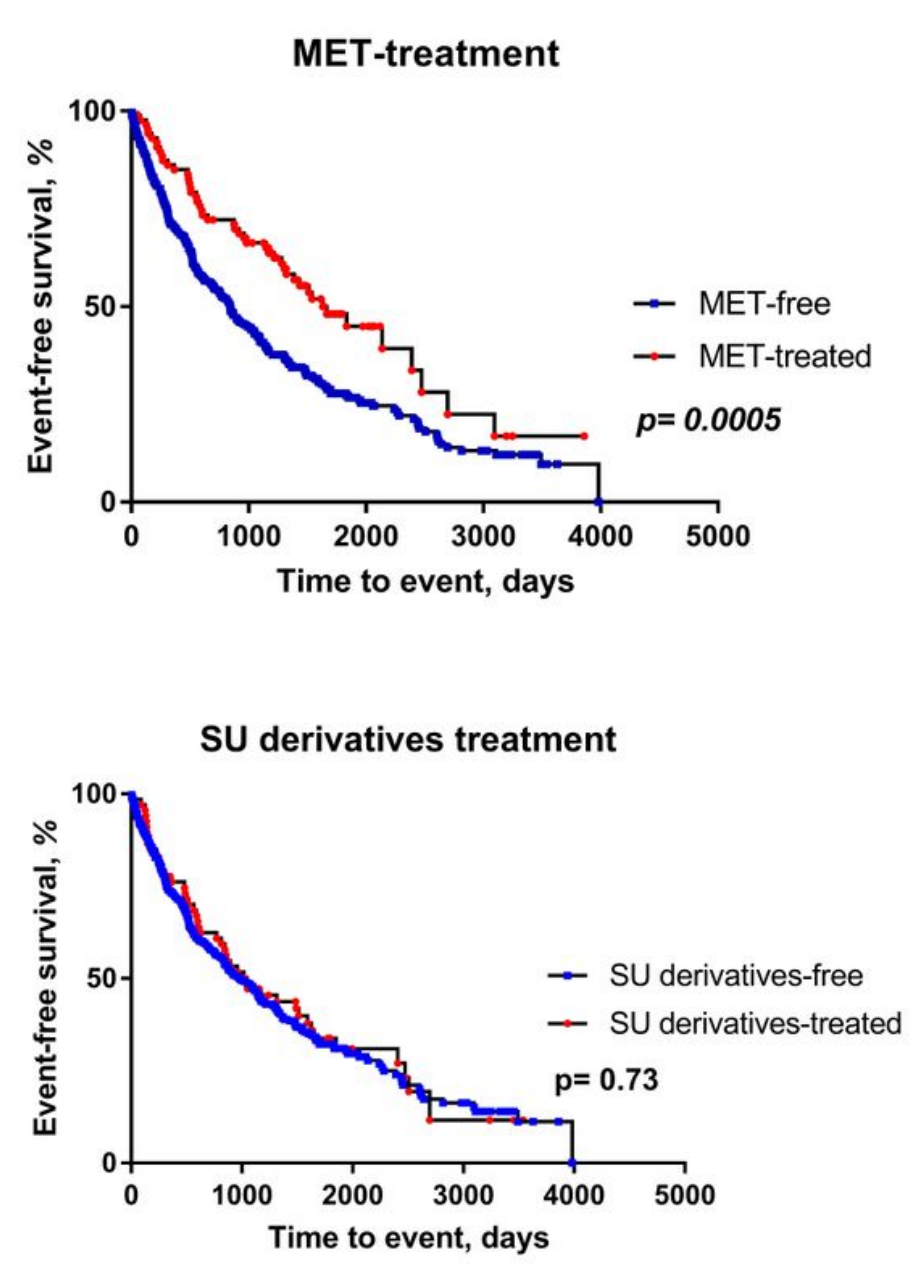
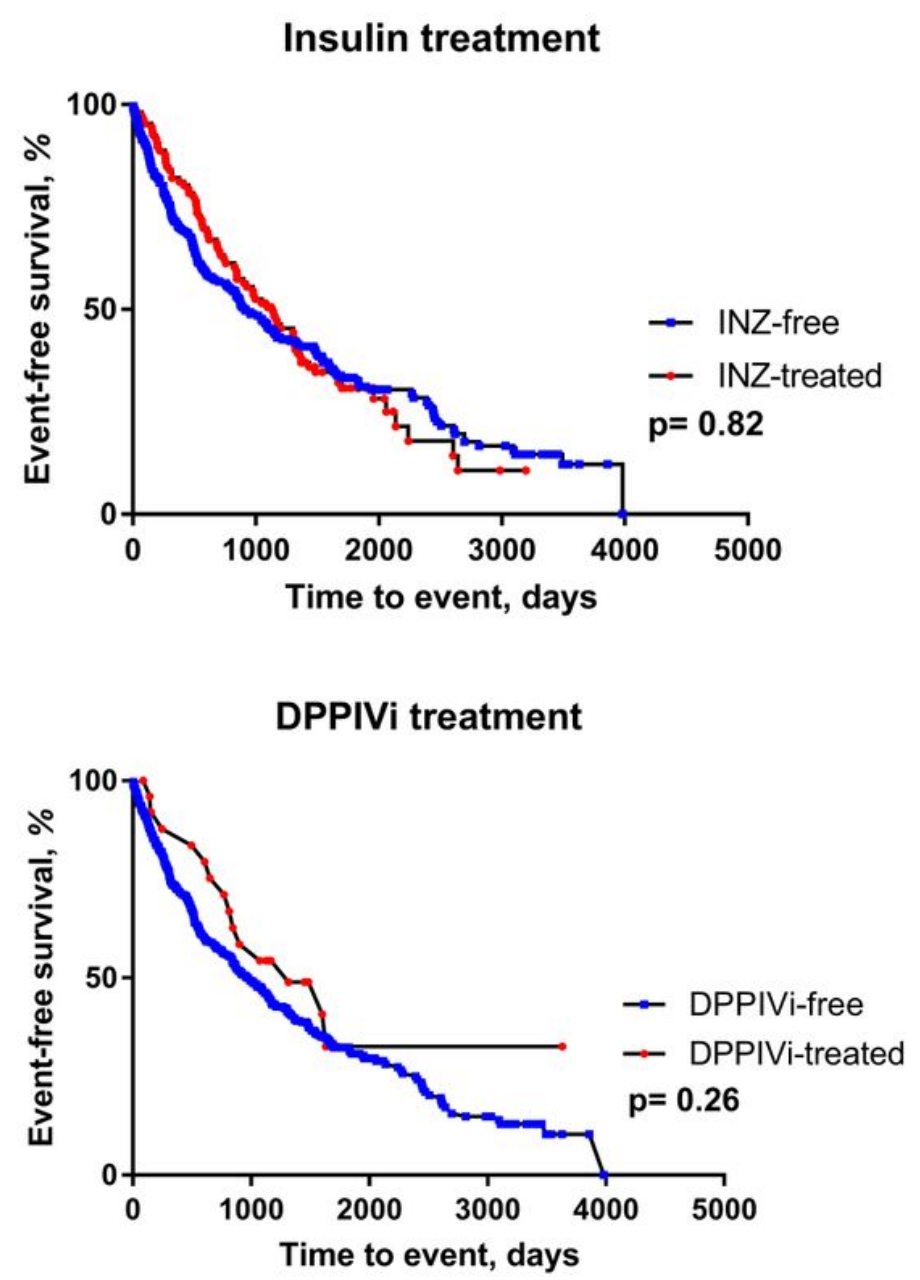

\section{Figure 4}

Event-free survival DM patients according DM treatment; MET-treated DM

patients had significantly better survival, no significant difference in survival was observed among patients treated with other glucose-lowering agents. 


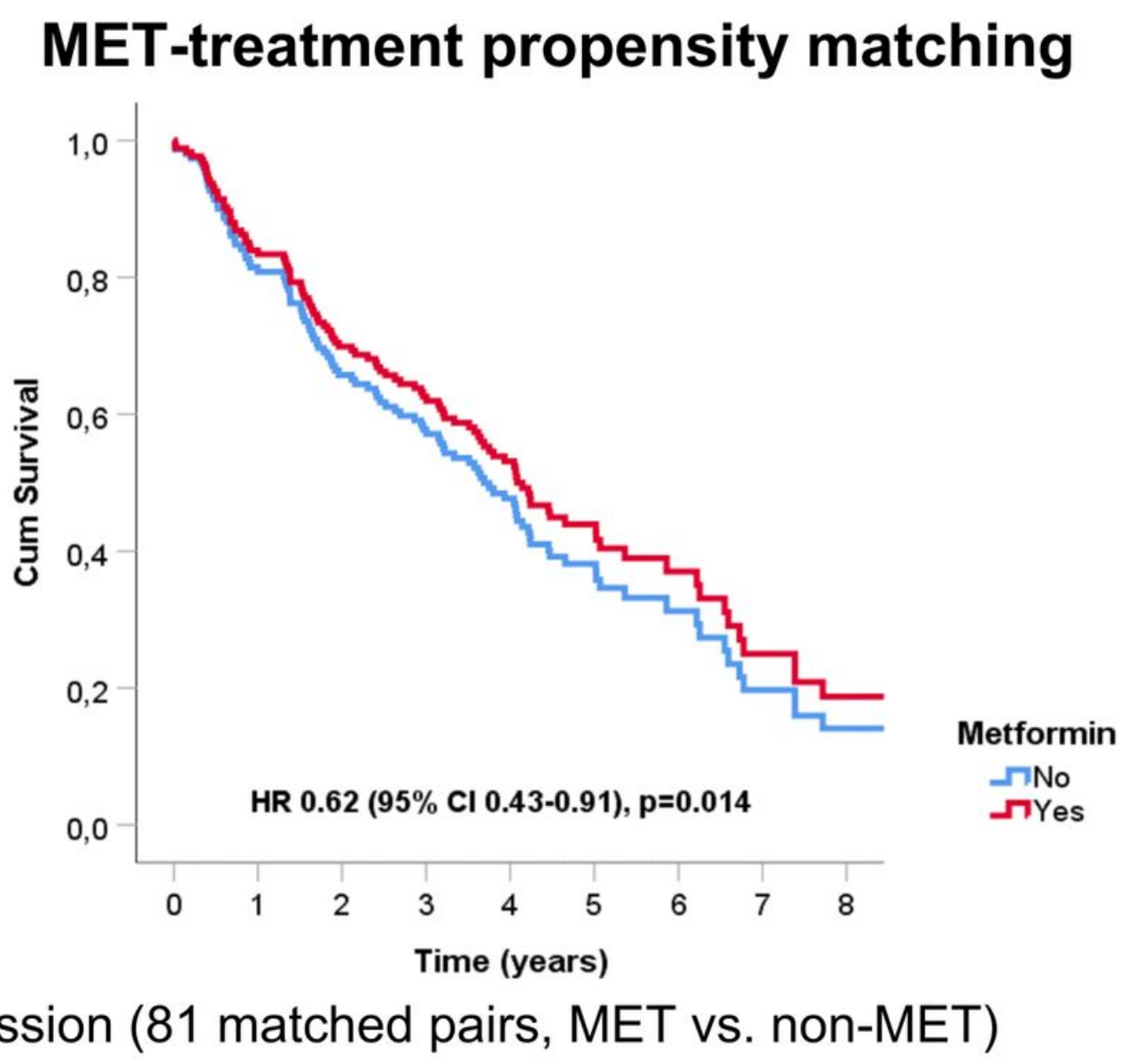

Adjusted for 17 variables (age, sex, NYHA, BMI, eGFR, LVEF, RV dysfunction grade, mitral regurgitation severity, tricuspid regurgitation severtiy, BNP, beta-blocker use, RAA-inhibitors use, ICD treatment, CRT treatment, uric acid, PAD/incretin treatment, insulin treatment)

Figure 5

Survival of MET-treated patients, propensity-score matched analysis

BMI- body mass index, eGFR- estimated glomerular filtration rate, LVEF- left

ventricle ejection fraction, RV-right ventricle, BNP- B-type

natriuretic peptide, RAAi- renin-angiotensin system inhibitors

ICD - implantable cardioverter/defibrillator, CRT - cardiac resynchronization

therapy, PAD- peroral antidiabetics

\section{Supplementary Files}


This is a list of supplementary files associated with this preprint. Click to download.

- SupplementaryFigure1.jpg

- SupplementaryFigure2.jpg

- SupplementaryTable1.docx

- SupplementaryTable2.docx

- SupplementaryTable3.docx

- SupplementaryTable4.docx 